\title{
Distal renal tubular acidosis with anemia
}

\author{
INSERM
}

\section{Source}

INSERM. (1999). Orphanet: an online rare disease and orphan drug data base. Distal renal tubular acidosis with anemia. ORPHA:93610

Distal renal tubular acidosis ( $\mathrm{dRTA}$ ) with anemia is a very rare form of distal renal tubular acidosis ( $\mathrm{dRT}$ A; see this term) characterized by a defect in renal acidification and hereditary hemolytic anemia. 